\title{
Erratum to: Duodenum-Stomach Anastomosis: a New Technique for Exocrine Drainage in Pancreas Transplantation
}

\author{
M. M. Linhares - R. I. Beron - A. M. Gonzalez • C. Tarazona • A. Salzedas • \\ E. B. Rangel • J. R. Sá • C. Melaragno • S. M. Goldman • M. G. Souza • N. Y. Sato • \\ D. Matos • G. J. Lopes-Filho $\cdot$ J. O. Medina
}

Published online: 11 November 2014

(C) 2014 The Society for Surgery of the Alimentary Tract

Erratum to: J Gastrointest Surg

DOI 10.1007/s11605-011-1806-1

Journal of Gastrointestinal Surgery, January 19th, 2012

Regarding the article "Duodenum-Stomach Anastomosis: a New Technique for Exocrine Drainage in Pancreas Transplantation" by Linhares MM, Beron RI, Gonzalez AM, Tarazona C, Salzedas A, Rangel E, Sá JR, Melaragno C, Goldman SM, Souza MG, Sato NY, Matos D, Lopes-Filho GJ, Medina JO which appears in the online first articles of Journal of Gastrointestinal Surgery (January 19th, 2012).

There is an error in the spelling of the sixth author's name. The correct name is Rangel EB.

The online version of the original article can be found at http://dx.doi.org/ 10.1007/s11605-011-1806-1.

M. M. Linhares · R. I. Beron · A. M. Gonzalez · C. Tarazona •

A. Salzedas • M. G. Souza • N. Y. Sato • D. Matos • G. J. Lopes-Filho

Department of Surgery, Federal University of Sao Paulo, São Paulo,

Brazil

M. M. Linhares $(\triangle)$

R. Pedro de Toledo, 980, Cj.-152/153, CEP-04039-002 São Paulo,

Brazil

e-mail: marbet@uol.com.br

E. B. Rangel $\cdot$ C. Melaragno $\cdot$ J. O. Medina

Department of Nephrology, Federal University of Sao Paulo,

São Paulo, Brazil

J. R. Sá

Department of Endocrinology, Federal University of Sao Paulo,

São Paulo, Brazil

S. M. Goldman

Department of Radiology, Federal University of Sao Paulo,

São Paulo, Brazil 